\title{
Study on Action Mechanism of Industrial Development Supported by National Quality Infrastructure
}

\author{
Hui Liu \\ China National Institute of Standardization \\ Beijing, China \\ Liuhui2604@163.com
}

\begin{abstract}
NQI includes metrology, standards, certification and accreditation, inspection and testing, and other basic elements which are closely related and interacted with each other, forming a systematic and organic whole. With the continuous development of social progress, NQI gradually presents the fundamentality, integrity, public welfare, internationalism and other denotation features. This study emphasizes on the analysis of the important functions of NQI in product quality enhancement and industrial quality improvement, efficiency increase, \& upgrading. In order to further strengthen the promotion function of NQI in quality enhancement and industrial development, this study finally presents the countermeasures and suggestions in terms of NQI top-level system design, the development \& enforcement of NQI strategic planning, the establishment of coordination \& development mechanism, the enhancement of talent te am and others.
\end{abstract}

Keywords-NQI, Connotation, Denotation, Quality Improvement, Industry Development

\section{INTRODUCTION}

In 2005, the "National Quality Infrastructure" (NQI) concept was put forward in the Export Strategic Innovation report released by the United Nations Conference on Trade and Development (UNCTAD) and World Trade Organization (WTO). Afterwards, it is further clearly stated in Rapid Development, Conformity Assessment \& Trust Transfer and other series of books jointly published by the United Nations Industrial Development Organization (UNIDO) and International Organization for Standardization (ISO) that metrology, standards, and conformity assessment are the three major pillars to form the NQI, three of which are interrelated \& inseparable, jointly laying a firm foundation for the national economic \& social development and trade capacity building. In 2007, the Germany PTB and other institutions jointly publish the "The Solution to Global Quality Challenges: National Quality Infrastructure”, which is intended to help the individuals and government departments to play a better role in the establishment of a unified and effective NQI, and facilitate the products or services of small-and-medium-sized enterprises to satisfy the quality demands of international market [1]. In 2011, the World Bank publishes the report Quality Control of East Europe and Middle Asia in the Global Competition. This report defines the definition and framework of NQI, describes the evolution pattern of NQI in market economy countries, and proposes the existence of critical point transiting from the public sector management to business organization management. In 2013, World Bank publishes the report National Quality Infrastructure: Effective Tool to Protect the Competitiveness, Trade and Social Welfare, which discusses in details the basic role of NQI in enhancing the international competitiveness and promoting the perfection of social welfare

The Study of NQI in China is just at the beginning stage. In 2014, Chinese Academy of Engineering launches the "Building a Robust Foundation for Industrial Development Strategic Study" major consultation project, carrying out the preliminary theoretical study of NQI. In the same year, General Administration of Quality Supervision, Inspection and Quarantine of the People's Republic of China conducts the "Industrial Quality Technical Infrastructure (IQTI) Strategic Study", and analyze the requirements of Industrial "Three Basics”, developing \& strengthening the construction path of IQTI in terms of standards, metrology, certification and accreditation, inspection and testing, and other aspects, supporting the objectives of "Building a Robust Foundation for Industrial Development" and "manufacturing power”. In 2015, the National Key R \& D Plan "Research and Application of Common Technology of NQI" is officially approved. According to the idea of the whole chain design and integrated implementation, this special project focuses on the industrial transformation and upgrading, safeguarding and improving people's livelihood, and enhancing the international competitiveness, and other significant national demands, and sets up 11 key tasks and 35 subtasks in the aspects of metrology, standards, conformity assessment, typical demonstration application and others[2].

\section{CONNOTATION \& DENOTATION OF NQI}

\section{A. Connotation of NQI}

NQI refers to the national quality and technical system framework, required for establishment and execution of metrology, standards, certification and accreditation, inspection and testing and others, to ensure that the products and services on the market will satisfy the technical requirements of manufacturer and regulator, and the actual requirements of customers [3]. 
NQI is intended to solve the accuracy of quantity values via metrology. In view of the technical attributes of metrology, metrology is the activity which can realize the unified unit and accurate \& reliable quantity values, making the measurement results of all the application fields have credibility. Without the accuracy of metrology, the design of the parameter data in the standards will lack of the premise. The mutual recognition of metrology sets up the platform for the scientific \& fast development of certification and accreditation, and strongly supports the mutual recognition system of International Laboratory Accreditation Cooperation (ILAC). Metrology is the significant condition which can ensure the accuracy of inspection and testing, while metrology is used to ensure the accuracy \& reliability of measurement. From the perspective of large scale metrology, inspection \& testing is the external application demonstration of metrology.

NQI will solve the consistency of rules via the standards. In view of the technical attributes of standards, standardization is the necessary condition to realize the collaboration \& transfer of metrology works. Metrology shall develop the standards of metrology terms, the quality \& verification standards of metrology testing equipment \& tools, standards of testing methods and transfer of quantity values, so as to normalize the metrology works. Standards provide the basic evidence for the certification and accreditation of products and processes, and ensure the mutual recognition and comparability of certification works. Standards provide the necessary criteria of testing data and testing methods to inspection \& testing, and also provide the basic support for the consistency of evidence and procedure of inspecting \& testing activity.

NQI will solve the fairness of support capacity of activity entity via certification and accreditation. In view of the technical attributes of certification and accreditation, certification and accreditation is the most significant and effective method to push the enforcement of standards, which has the feedback and perfection functions for standards. The laboratory accreditation is the effective method to improve the technical capacity of calibration laboratories and also realize the international traceability. Measurement management system certification can effectively enhance the enterprise metrology management capacity, supervise and instruct the enterprises to establish the measurement management system as per the international advanced metrology testing management model. The certification and accreditation is the internationally feasible means to verify the equality and capacity of inspection \& testing, and also the effective measures to avoid the repeated inspection \& testing.

NQI will solve the conformity of quality via inspection \& testing. In view of the technical attributes of inspection \& testing, inspection \& testing takes the quality conformity assessment, technical performance testing, and risk control as the core, and uses the technology of chemistry, physics, biology, statistics, and information science as the foundation, to develop the special testing equipment, establish testing methods, and develop the relevant standards. Besides, the inspection \& testing will maintain the proper operation of social economy and protect the human health, life and property security, national security and ecological environment security, by continuously expand the testing scope, enhance the testing accuracy, extend the testing fields, and perfect the methods and standards system.

\section{B. Denotation of NQI}

In a certain sense, NQI is the significant carrier for the economic \& social development and technical transfer of human beings. With the continuous development of social progress, NQI is also gradually evolving, while the denotation derived from connotation becomes continuously enriched, developing some unique denotation features.

\section{1) Fundamental Denotation Features of NQI}

NQI plays a fundamental role in the economic \& social development. Metrology has a close relation with the national security, and symbolizes the national power and social justice. The establishment and stability of state power must be guaranteed with unified and authoritative metrology. At the macro-national level, standards provide the technical rules for the economic \& social development, and are the national fundamental system. The certification and accreditation is a sort of tool to build and transfer credit under the environment of market economy, and also the key element and fundamental pillar to construct the quality management and market supervision system. Through the technical assessment of products/ services, certification and accreditation provides the precise quality signal to the society, and is the significant technical foundation of product/ service quality enhancement. From the perspective of its own development of NQI, NQI will enhance the industrial core competitiveness, safeguard and improve the people's livelihood, and promote the economic and social sustainable development, by fully protecting the product quality safety.

\section{2) Integral Denotation Features of NQI}

From the perspective of the functions of NQI in enhancing the quality level, NQI is an indivisible whole. Metrology will provide the benchmark and transfer of quantity values of quality, while the standards reflect the basis of quality and leads the quality enhancement, and certification \& accreditation, and inspection \& testing controls the quality and also builds the quality trust. Standards are the basis of metrology, certification \& accreditation, and inspection \& testing, and metrology is the benchmark of standards and certification \& accreditation, and inspection \& testing, while certification \& accreditation, and inspection \& testing are the significant methods to push the standards enforcement and metrology traceability level enhancement. All of them form a complete technical chain, mutually acted, supported and supplemented, and jointly promoting the development of quality.

\section{3) Public Welfare Denotation Features of NQI}

The metrology and standards in the NQI have the features of public goods, while the certification \& accreditation, and inspection \& testing have the features of quasi-public goods. From the perspective of constitution contents, the public goods features of metrology and standards are reflected in that during the process of their detailed technical contents, equipment and technical means being utilized by one enterprise, the utilization of their metrology and standards by other enterprises will not be affected, while the quasi-public goods features of 
certification \& accreditation, and inspection \& testing are demonstrated in that the provision and usage of such services will not affect the certification \& accreditation, and inspection \& testing behaviors of other enterprises, although commercial behaviors may exist during the process of such service. As a whole, the fundamental theory and application methods of metrology, standards, certification and accreditation, inspection and testing have the features of public scientific research. All countries have invested a lot of financial funds into these fields, to support the national public output in NQI.

\section{4) International Denotation Features of NQI}

As the internationally used "technical language", the NQI taking the metrology, standards, certification and accreditation, inspection and testing as the core elements is the significant component of international trade rules. It is definitely stated in WTO/TBT agreements to deem standards, technical regulations, and conformity assessment as the Technical Barriers to Trade (TBT) used for maintaining the national or regional security, protecting the human health and security, protecting the life and health of animals and plants, protecting the environment, ensuring the product quality, and preventing fraud. Taking standards as an example, as the three major international authoritative standardization institutions, the standards developed by International Standardization Organization (ISO), International Electro technical Commission (IEC) and International Telecommunication Union (ITU) have a significant impact upon the international trades. Therefore, it becomes the standardization strategic key points of every country, especially the developed countries, to compete for the leadership and voice of development of international standards.

\section{ACTION MECHANISM OF PRODUCT QUALITY ENHANCEMENT SUPPORTED BY NQI}

\section{A. Standards Are the Foundation and Evidence of Ensuring the Product Quality}

Standards are a kind of used and reused normative documents that are developed by consensus and approved by recognized institutions, so as to obtain the best order within the specific limits[4]. During the production process of enterprises, either for all materials ranging from raw materials, components \& parts, to final products, or for whole life cycle ranging from design, manufacture, distribution, usage, to maintenance, the guarantee of product quality is closely related to a series of standards. Standards specify the quality characteristic index, and become the criteria for determining quality, which specify the specific and definite measurement scale of quality conformity. Meanwhile, standards are also the specification and quantification of quality management and supervision targets in product quality, inspection methods, pattern, specification, dimension, packing and others. Therefore, the enterprise production quality standard system is required to be more perfect, while the product quality safety index shall reach the requirements of national compulsory standards, to entirely realize the standardization of product quality, service quality and engineering quality.

\section{B. Metrology Provides the Technical Conformity Evidence for Quality}

The product quality depends on the application \& development level of materials, process, technology and equipment, and also relies on the quality control of every link in the product production process, which shall can be effectively ensured and proved with accurate and reliable metrology means and data. Metrology can realize the consistency and interchangeability of the equivalent product made by variable enterprises, and assess the metrology of product performance, function, environmental impact, and safety[5].Without the support of reliable metrology and inspection technology, the product quality of enterprises will not be guaranteed. It is desired that the quality, safety, interoperability, efficiency, and environmental sustainability of products and services shall conform to the required specifications. All sorts of measurement must be traceable to international and national measurement standards, realizing the accuracy, consistency, reliability and efficiency of measurement results. In this manner, the consistency and interchangeability between product quality and standards, and the fair competition of quality of equivalent products among variable enterprises can be ensured.

\section{The Certification \& Accreditation Can Enhance the Safety Level of Product Quality}

Product is the trading entity, especially the products involving the safety \& health, while the protection of product usage safety has a significant meaning for consumer protection. The product safety refers to product performance of protecting the human health or safety, and life or health of animals \& plants during the product usage \& storage process[6]. For any product involving the protection of the human health or safety, and life or health of animals \& plants, many countries worldwide have developed the special safety standards and enforce the compulsory certification upon the aforesaid products through the governmental laws and regulations, namely, legal certification. China Compulsory Certification (3C Certification), has already developed the relatively complete compulsory product certification system construction and supervision system construction, so as to protect the personal safety of consumers and life security of animals \& plants, ecological environment and national information security.

\section{Inspection \& Testing Safeguards the Enhancement of Product Quality}

Inspection \& testing is the spontaneous product of commodity exchange activities under the environments of market economy, referring to the technical assessment activity which is intended to check whether the product, service and management system conform to the standards, technical specification and compulsory requirements[7]. When the suppliers and buyers want to satisfy their own demands, or when the arbitration department shall determine the product quality disputes of relevant products, the inspection \& testing of product quality shall be made by relying on a certain technical institution, utilizing a certain technical means and as per a certain standards. The technical and experimental data of 
inspection \& testing can feedback the quality information to producers, customers and administers, while inspection \& testing, especially the independent third-party inspection \& testing is one of the significant means to reduce the degree of the information asymmetry.

\section{ACTION MECHANISM OF INDUSTRIAL QUALITY AND EFFICIENCY UPGRADING SUPPORTED BY NQI}

\section{A. Standards Are the Effective Lever to Adjust the Industrial Structure}

Standards are the vital threshold to normalize the orderly development of industry and close down outdated production facilities. The excess capacity is the most prominent problem that affects the present development of China's manufacturing industries. The excess capacity problems in steel, cement, plate glass and other industries become more prominent. The shutdown of outdated production facilities and scientific integration of capacity are related with the healthy development of industry, and the reasonable deployment of productivity[8].On one hand, standards can force the government to consciously push and realize the adjustment and optimization of industrial structure, effective integration of standards and industrial policy, adjustment of the present industrial structure, optimization of industrial development path and acceleration of industrial upgrading pace. On the other hand, the market force may be used to shut down the backward modes of production, and lead the relevant industries to come back on the track of sound development[9]. Under the action of market competition mechanism, the development \& enforcement of standards may strengthen the market competitiveness of up-to-standard products, improve the production and management costs of those enterprises that don't enforce the standards, control the production scale and market share of highly polluting and highly energy-consuming enterprises, and close down the production technology and modes that does not conform to the market development trend.

\section{B. Metrology Is the Significant Technical Foundation of Industrial Development}

The advancement of industrial core technology and key generic technology is demonstrated by indexes of key parameters, while the key parameters can be accurately evaluated and effectively controlled only through the metrology testing. Whether the core technology of industrial development can be broken through is mainly determined by whether the core metrology and testing technology can be broken through[10].In case that the metrology and testing technology can neither satisfy the major technical requirements of industrial development, nor solve the metrology and testing problem of core technology in the industrial key areas, it will definitely constrain the industrial development. Therefore, the testing technical capacity and level of key parameters in the industrial key areas is a significant factor to restrict the industrial development. With the rapid development of modern industry systems, especially the emerging of major industries represented by strategic emerging industries, the metrology technology will make significant contributions to enhance the industrial core competitive services, improve the measurement technical capacity and level of key parameters of industrial key fields, solve the measurement technical difficulty of core technical key parameters of industrial development, and crack the technical bottleneck restricting the development of major industries.

\section{Certification \& Accreditation Can Guide Industrial Transformation and Upgrading}

The certification \& accreditation may guide the rapid technical progress of enterprises and promote the industrial \& economic transformation \& upgrading through technical assessment means. Meanwhile, it can promote the enterprises to perform the better social responsibilities in labor protection, environmental protection, and others, protect the health and safety interests of employee, and promote the energy saving, consumption \& emissions reduction. Furthermore, it can also maintain the harmony between human and nature, and economy and society, and promote the economic \& social sustainable development. The certification \& accreditation gradually emerge in the energy saving \& emissions reduction, environmental protection, new energy, low carbon technology, green trade and other major fields of global sustainable development, and become the significant means of promoting the economic \& social sustainable development of each country.[11]

\section{Inspection \& Testing Serves the Industrial Quality and Efficiency Upgrading}

The technical and experimental data of inspection \& testing are the significant foundation and evidence of industrial structure adjustment and optimization \& upgrading, and can feedback the quality information to producers, consumers and administers. The inspection \& testing, especially the independent third-party inspection \& testing is one of the significant means to reduce the degree of the information asymmetry. The establishment of public welfare inspection \& testing public service platform, can effectively promote the industrial agglomeration and development, playing the "Building a Nest to Attract the Phoenix" role in the development of emerging industries[12]. The strengthening test, reliability \& life test, and product quality inspection \& testing and other inspection \& testing technology and data of basic parts, elements and materials are the significant guarantee and evidence of "Three Basics" product quality level, and the significant technical means of promoting the industrial structure upgrading.

\section{COUNTERMEASURES \& SUGGESTIONS OF QUALITY ENHANCEMENT \& INDUSTRIAL DEVELOPMENT PROMOTED BY} NQI

\section{A. Strengthening the Top-Level Design}

It is necessary to strengthen the top-level design \& research of NQI, deepen the comprehensive and integrated reform from the top-level design, promote the reform innovations taking change the government function as the core, and perfect the quality infrastructure governance system integrated with the world market. At the enforcement level, it is intended to realize the synergetic development of standards, metrology, 
certification \& accreditation, inspection \& testing, industry and technology. Through constructing the four-in-one NQI structure of objects, events, people and technology, the triple helix development trend taking scientific metrology, certification \& accreditation and standards as the core shall be developed, while the government-enterprise-public-oriented national quality value community shall be constructed, fully exploiting the reform bonus, inner potential and innovative vitality of national development of quality.

\section{B. Developing \& Enforcing the Strategic Plan}

Based on the development requirements of NQI, it is necessary to determine the general idea, development goals, key task, and implementation path, incorporate the NQI construction into the national governance system, develop the medium-and-long-term plan, define the guiding ideology, target tasks, and policy measures, and support the national social \& economic development.

\section{Forming the Synergetic Development Mechanism}

It is required to form the interactive mechanism of NQI and industrial synergetic development, straighten out the present quality management system and mechanism, strengthen the present coordination function of General Administration of Quality Supervision, Inspection and Quarantine of the People's Republic of China, and coordinate the participation initiative and efficiency of variable stakeholders during the quality governance process. On one hand, it is required to formulate the relevant mechanism and emphasize the participation of stakeholders (government, research institutions, colleges and universities, enterprises, associations, standardization organizations, consumers, and others) in the R \& D and enforcement works of NQI. On the other hand, it is required to continuously perfect and strengthen the management and coordination works of NQI strategy enforcement. It is required to enhance the operation and organization mechanism of different entities by formulating the corresponding policies and measures.

\section{Strengthening the Building of Talent Team}

It is required to perfect the national education discipline system of quality related disciplines, push the construction of quality related disciplines, and encourage the setup of quality education research institution in colleges and universities. It is required to develop the quality occupational technical education and reform and perfect the vocational qualification examination system of quality majored technician and relevant supporting policies. It is required to extensively carry out the quality education \& training for enterprises in vocational colleges, strengthen the technical specification, operation technique, and quality knowledge training for industrial workers, and implement the vocational skills upgrading scheme of migrant workers. Besides, it is also required to strengthen the quality related expert team building, establish the Advisory Committee for State Quality Experts, and strengthen the education and enhancement of young talents of quality science and technology.

\section{CONCLUSION}

As the significant tool of establishing the best order of economic and social activity, NQI is the fundamental guarantee of pushing the economic \& social transformation and upgrading, and realization of the connotative \& intensive development. It has the significant function in promoting the overall level enhancement of China's NQI, to fully understand the function mechanism of NQI in supporting the product quality enhancement and industrial quality and performance improvement, to strengthen the NQI top level design, develop the NQI enforcement strategic planning, form the NQI coordinated development mechanism, strengthen the NQI talent team building and generic platform construction. The overall level enhancement of NQI, has a significant impact upon the in-depth enforcement of Guideline regarding Carrying out Quality Enhancement Act developed by the CPC Central Committee and State Council, enforcement of manufacturing power strategy, and realization of Made in China 2025 strategic targets.

\section{ACKNOWLEDGMENT}

This research was financially supported by the President Foundation of CNIS (572018Y-5937) and National Key Research and Development Program (2016YFF0204206).

\section{REFERENCES}

[1] Clemens Sanetra, Rocio M.Marban. The answer to the global quality challenge: a national quality infrastructure. PTB et.al. 2007.

[2] AQSIQ, Department of Science and Technology. NQI:Strengthen quality powerful country, Lead economic and social development,2016(4) p.28-30.

[3] Strategic Advisory Committee on the construction of national manufacturing powers, Strategic consulting center of the Chinese Academy of Engineering. High quality manufacturing, China Industry and Information Technology Publishing and Media Group, Publishing House of Electronics Industry,2016.

[4] Guidelines for Standardization- Part 1: Standardization and related actives- General Vocabulary.

[5] Linfeng Li. Discussion on the role of Metrology and inspection technology in quality and technology supervision. Science and Technology Prospect, 2016(6), p.311.

[6] Xuliang $\mathrm{Wu}$, Zhaojin Large sales competition, quality gap and product safety regulation .Sun. Industrial Economics Research,2016,(2).p.43-50.

[7] Douwen Wang, Yun Deng. Uncertainty evaluation of quality control technology in inspection and testing laboratories, China Zhijian Publishing House, 2017.

[8] Hong Fei. The direction and path of the current industrial transformation and upgrading in China, Microeconomics, 2017,(2), p.31-38.

[9] Zhou Deng. Importing of technical standards and development of strategic emerging industries. Economic management,2014,(7).p.19-30.

[10] Aiwen Ma. Reflection on the fourth industrial revolution to metrology test. Industrial measurement,2015,(2).p.1-4.

[11] Zende Xu. National Quality Infrastructure: The development of Certification and Accreditation, Shanghai Quality, 2015,(12),p.11-14.

[12] Di He, Shuxiang Xing. Study on the development of China's inspection and Inspection Service Outsourcing: Based on the perspective of the contractor, Practice in Foreign Economic Relations and Trade,2013,(6), p.84-86. 